\title{
Chance, often an Ignored Factor in Genetic Studies
}

\section{Bernt Lindelö ${ }^{\star}$}

Department of Medicine, Unit of Dermato-Venereology, Karolinska University Hospital and Karolinska Institute. S-171 76 Stockholm Sweden

Genetic studies have made a substantial progress in identifying the genetic basis of many human diseases. However, search for genes or loci that might underlie a disorder among family members have sometimes been disappointing, especially if the disorder is common.

One reason for that could be not considering chance association among family members affected by the disorder. For example among 158868 females with breast cancer, 5088 first-degree relatives could be identified ${ }^{1}$. Noteworthy, in the matched (by year of birth, sex and year of death) control cohort with the same number of healthy females, no less than 3326 first-degree relatives were found (65\%) and thus representing the normal hereditary component of such a big cohort.

The impact of chance association in searching for genes in firstdegree relatives for some other common forms of cancer can be estimated from that study [1].

\section{Most affected cancer by chance:}

Stomach

Breast

$65 \%$

Urinary organs
Colon
$53 \%$
Lung

Least affected cancer by chance:

Eye $6 \%$

Testis

Hodgkin's disease

Thyroid gland

$16 \%$

Thus, when performing genetic studies on family members with a certain form of cancer, one has to be aware of the chance association. Even though a mother and her daughter both have breast cancer there is only $35 \%$ of such pairs that are true genetic and this must be considered when interpreting the result.

\section{References}

1. Lindelöf B, Eklund G. (2001) Analysis of hereditary component of cancer by use of a familial index by site. Lancet 358: 1696-98.
*Corresponding author: Bernt Lindelöf Department of Medicine, Unit of DermatoVenereology, Karolinska University Hospital and Karolinska Institute. S-171 76 Stockholm Sweden, E-mail: Bernt.lindelof@karolinska.se

Received December 01, 2011; Accepted December 10, 2011; Published december 14, 2011

Citation: Lindelöf B (2012) Chance, often an Ignored Factor in Genetic Studies. Hereditary Genetics 1:102. doi:10.4172/2161-1041.1000102

Copyright: (c) 2012 Lindelöf B. This is an open-access article distributed under the terms of the Creative Commons Attribution License, which permits unrestricted use, distribution, and reproduction in any medium, provided the original author and source are credited. 